\title{
Treatment Outcome and Predictors of Survival in Thai Adult Rhabdomyosarcoma Cases
}

\author{
Aumkhae Sookprasert ${ }^{1}$, Piti Ungareewittaya ${ }^{2}$, Areesa Manotepitipongse ${ }^{1}$, Kosin \\ Wirasorn $^{1}$, Jarin Chindaprasirt ${ }^{1 *}$
}

\begin{abstract}
Background: Adult rhabdomyosarcoma (RMS) is a rare and aggressive disease with limited data compared with pediatric RMS. The goal of this study was to determine the treatment outcome and identify factors related to survival outcome in Thailand. Materials and Methods: Adult patients ( $\geq 15$ years old) with the pathological diagnosis of RMS between 1985 and 2010 were reviewed. The data were retrospectively reviewed from the pathological results and medical records from Srinagarind Hospital, Khon Kaen University. Results: A total of 34 patients were identified in the study. The median age at diagnosis was 35.5 years and the most common primary sites were extremity and the head and neck region. The incidence of pleomorphic RMS increased with age and none was found in those aged younger than 20 years old. The median survival time was 9.33 months (95\% CI: 5.6-13.1). The 1- and 5- year survival rates were 38.2\% (22.3-54.0) and 20.6\% (9.1-35.3). On multivariate analysis, age and size of tumor did not predict better outcome while chemotherapy and surgery were significantly associated with longer survival. Conclusions: Outcome of adult RMS was poor. Surgery and chemotherapy are strongly associated with better prognosis and multimodality treatment should be incorporated in the clinic.
\end{abstract}

Keywords: Rhabdomyosarcomas - adults - outcome - survival - prognostic factors -Thailand

Asian Pac J Cancer Prev, 17 (3), 1449-1452

\section{Introduction}

Even though rhabdomyosarcoma (RMS) is found frequently in children, it is an uncommon cancer in adults. It accounts for only $2-5 \%$ of all adult soft tissue sarcoma (Ferrari et al., 2003). Three main subtypes of RMS are embryonal, alveolar, and pleomorphic variants. Pleomorphic RMS occurs mainly in adults while the other two histologies are commonly represented in pediatric RMS (Newton et al., 1995; Parham and Ellison, 2006). With increasing age, the incidence of pleomorphic RMS increases and the prognosis is poor (Simon et al., 2003).

Multimodality treatment including chemotherapy, radiation, and surgery has been the mainstay of treatment of this rare disease, even though the data is limited (Esnaola et al., 2001; Little et al., 2002; Ferrari et al., 2003). Chemotherapy regimens are derived primarily from pediatric data. A combination of vincristine, dactinomycin, cyclophosphamide (VAdCy) is the most widely used regimen (Arndt et al., 2009). But other anthracyclines (doxorubicin and epirubicin), ifosfamide, etoposide, and carboplatin have also shown activity and are effective in RMS (Arndt et al., 2008; Sezgin et al., 2015).

Survival outcomes for adult RMS in many earlier reports are poor; the 5-year overall survival rates were 27$40 \%$ (Ferrari et al., 2003; Sultan et al., 2009). Prognostic factors for survival were age, histologic subtype, primary site of origin, stage, and local control with surgery or radiation (Sultan et al., 2009).

The objective of this study is to review the experience of adult RMS in our institution and to define clinical presentation and clinicopathological factors that predict survival outcome.

\section{Materials and Methods}

All adult patients (age $\geq 15$ years) with a pathological diagnosis of RMS who were treated at Srinagarind hospital, Khon Kaen University between 1985 and 2010 were included in the study. Clinical and pathological data were retrospectively reviewed.

The survival rate was analyzed using the standard survival function in SPSS version 22.0 and presented on a Kaplan-Meier curve. The survival experiences for each treatment group were compared using the Log-rank test. Multivariate analysis of clinical factors predicting survival was conducted using the Cox proportional hazards model. A p-value of $<0.05$ was considered significant. 
Ethics appoval was provided by the Ethics Committee of the Faculty of Medicine, Khon Kaen University, under the guidelines of the Helsinki Declaration and Good Clinical Practice.

\section{Results}

\section{Patient demographics}

During the study period, a total of 34 patients for whom a pathologic diagnosis of RMS was confirmed was included. The clinicopathological characteristics are shown in Table 1. Male $(n=17)$ and female patients $(n=17)$ were presented equally. The median age at diagnosis was 35.5 years (range 15-89). The two most common primary sites were extremity $(35 \%)$ and head and neck region $(29 \%)$. There was one primary tumor from left atrium. Twenty-one patients had localized disease at diagnosis, while 13 were metastatic disease. The size of primary tumor was documented in 32 patients $(94 \%)$. Ten patients $(29 \%)$ had small tumors measuring $\leq 5 \mathrm{~cm}$, while 14 patients $(41 \%)$ had tumors larger than $10 \mathrm{~cm}$. At presentation, 21 patients $(62 \%)$ had localized disease, whereas 13 patients $(38 \%)$ had advanced disease.

\section{Pathology}

In this study group, the most common subtype was embryonal RMS (35\%). Forty percent of the tumor located

Table 1. Baseline Demographics and Tumor Characteristics

\begin{tabular}{|c|c|c|}
\hline Demographics & Number of cases & Percentage \\
\hline \multicolumn{3}{|l|}{ Gender } \\
\hline Male & 17 & 50 \\
\hline Female & 17 & 50 \\
\hline \multicolumn{3}{|l|}{ Age (yrs) } \\
\hline$<20$ & 7 & 20.6 \\
\hline $20-40$ & 11 & 32.4 \\
\hline$>40$ & 16 & 47.1 \\
\hline \multicolumn{3}{|l|}{ Primary tumor site } \\
\hline Extremity & 12 & 35.3 \\
\hline Visceral & 5 & 14.7 \\
\hline Head and neck & 10 & 29.4 \\
\hline Trunk & 7 & 20.6 \\
\hline \multicolumn{3}{|l|}{ Size $(\mathrm{cm})$} \\
\hline$\leq 5$ & 10 & 29.4 \\
\hline $5-10$ & 8 & 23.5 \\
\hline$>10$ & 14 & 41.2 \\
\hline \multicolumn{3}{|l|}{ Histological subtype } \\
\hline Embryonal & 12 & 35.3 \\
\hline Alveolar & 6 & 17.6 \\
\hline Pleomorphic & 11 & 32.4 \\
\hline Not otherwise specified & 5 & 14.7 \\
\hline \multicolumn{3}{|l|}{ Nodal involvement } \\
\hline Negative & 23 & 67.6 \\
\hline Positive & 11 & 32.4 \\
\hline \multicolumn{3}{|l|}{ Disease spread } \\
\hline Localized & 21 & 61.8 \\
\hline Metastatic & 13 & 38.2 \\
\hline \multicolumn{3}{|l|}{ Treatment } \\
\hline Surgery & 22 & 64.7 \\
\hline Chemotherapy & 17 & 50 \\
\hline Radiation & 14 & 41.2 \\
\hline
\end{tabular}

in head and neck region was embryonal tumor. Embryonal RMS was found mostly in younger patients, with $71 \%$ in age group 15-20 years, while only $6 \%$ in those age more than 40 years. On the contrary, pleomorphic subgroup was relatively more frequent in older age group and none was observed in patients younger than 20 years old (Figure 1). Although alveolar tumor was the least common subtype, the proportion of patients who had nodal involvement at presentation were significantly higher than those with embryonal/pleomorphic disease $(83 \%$ vs $21 \%$, Fisher exact test $\mathrm{p}=0.008$ ).

\section{Treatment}

Twenty-two patients underwent surgical resection (64\%) and external beam radiation was incorporated in the treatment in 14 patients $(41 \%)$. Fifty percent of the patients (17/34) received a combination of chemotherapy. Different regimens were administered including vincristine, dactinomycin, and cyclophosphamide (VAdCy regimen), ifosfamide and etoposide (IE regimen). Some patients also received a combination of anthracyclines and cisplatin/ carboplatin. Neoadjuvant chemotherapy was administered in six patients and half of them (three patients) were able

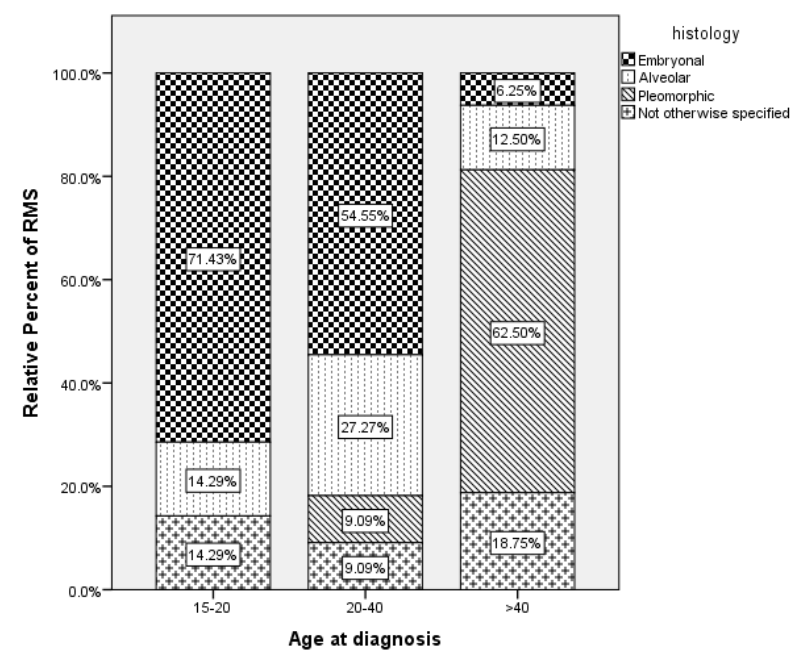

Figure 1. The Relative Frequency of the Pathological Subtypes of RMS

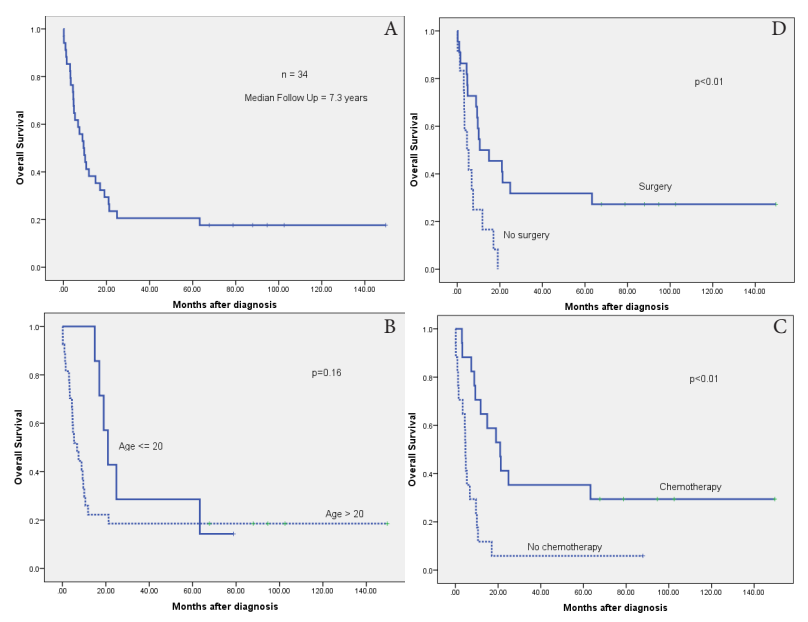

Figure 2. Overall Survival Rates. For all 34 Patients (A); Comparing Patient age (age $\leq 20$ years vs. age $>20$ yeras) (B); Comparing surgery vs. no surgery (C); Comparing chemotherapy vs. none (D) 
Table 2. Analysis of Overall Survival According to Patient, Tumor, and Clinical Characteristics

\begin{tabular}{|c|c|c|c|c|c|c|c|}
\hline \multirow{2}{*}{$\begin{array}{l}\text { Descriptor } \\
\text { Gender }\end{array}$} & \multicolumn{3}{|c|}{$\%$ 2-year survival } & $\%$ 5-year survival & \multicolumn{2}{|c|}{ Median survival (mo) } & \multirow[t]{2}{*}{$\overline{p \text {-value }}$} \\
\hline & & & & & & & \\
\hline Male & & 23.5 & & 17.6 & 7.43 & & \\
\hline Female & & 23.5 & & 17.6 & 10.07 & & 0.97 \\
\hline \multicolumn{8}{|l|}{ Age (yrs) } \\
\hline$\leq 20$ & & 42.9 & & 28.6 & 20.97 & & \\
\hline$>20$ & & 18.5 & & 18.5 & 6.77 & & 0.16 \\
\hline \multicolumn{8}{|l|}{ Subtype } \\
\hline Embryonal & & 33.3 & & 25 & 19 & & \\
\hline Alveolar & & 33.3 & & 16.7 & 9.6 & & \\
\hline Pleomorphic & & 18.2 & & 18.2 & 4.7 & & \\
\hline NOS & & 0 & & 0 & 8.8 & & 0.38 \\
\hline \multicolumn{8}{|l|}{ Primary tumor site } \\
\hline Extremity & & 25 & & 25 & 9.33 & & \\
\hline Visceral & & 20 & & 20 & 9.63 & & \\
\hline Head and neck & & 0 & & 0 & 6.77 & & \\
\hline Trunk & & 57.1 & & 42.9 & 24.87 & & 0.14 \\
\hline \multicolumn{8}{|l|}{ Size $(\mathrm{cm})$} \\
\hline$\leq 5$ & & 31.8 & & 28.6 & 10.07 & & \\
\hline$>5$ & & 10 & & 7.7 & 8.83 & & 0.86 \\
\hline \multicolumn{8}{|l|}{ Nodal involvement } \\
\hline Negative & & 30.4 & & 30.4 & 10.57 & & \\
\hline Positive & & 9.1 & & 0 & 7.43 & & 0.07 \\
\hline \multicolumn{8}{|l|}{ Extent of disease } \\
\hline Localized & & 33.3 & & 28.6 & 14.9 & & \\
\hline Metastatic & & 7.7 & & 7.7 & 4.7 & & $0.02 *$ \\
\hline \multicolumn{8}{|l|}{ Surgery } \\
\hline No & & 0 & & 0 & 4.57 & & \\
\hline Yes & & 36.4 & & 27.3 & 10.57 & & $<0.01 *$ \\
\hline \multicolumn{8}{|l|}{ Chemotherapy } \\
\hline No & & 5.9 & & 5.9 & 4.7 & & \\
\hline Yes & & 41.2 & & 35.3 & 20.97 & & $<0.01 *$ \\
\hline \multicolumn{8}{|l|}{ Radiation } \\
\hline No & & 15 & & 15 & 5.37 & & \\
\hline Yes & & 35.7 & & 28.6 & 14.9 & & 0.16 \\
\hline \multicolumn{4}{|c|}{ Table 3. Independent Predictors of Death } & \multicolumn{4}{|c|}{ Table 4. Review of 5-year Survival Rate of Adult RMS } \\
\hline Prognostic factor & $\begin{array}{l}\text { Hazard ratio } \\
\text { (adjusted) }\end{array}$ & $95 \% \mathrm{CI}$ & p-value & & & $\begin{array}{l}\text { No. of } \\
\text { patients }\end{array}$ & $\begin{array}{c}5-y r \\
\text { survival } \\
(\%)\end{array}$ \\
\hline Age $\leq 20$ years old & 0.73 & $0.23-2.25$ & 0.58 & \multirow{3}{*}{\multicolumn{2}{|c|}{$\begin{array}{l}\text { Ariel, } 1975 \text { (Ariel and Briceno, 1975) } \\
\text { Hawkins et al., } 2001 \text { (Hawkins et al., } \\
\text { 2001) }\end{array}$}} & 113 & 32 \\
\hline Size $\leq 5 \mathrm{~cm}$ & 0.93 & $0.32-2.72$ & 0.89 & & & & \\
\hline Nodal involvement & 1.39 & $0.50-3.88$ & 0.52 & & & 84 & 35 (EFS) \\
\hline $\begin{array}{l}\text { Metastatic disease at } \\
\text { presentation }\end{array}$ & 2.31 & $0.76-7.01$ & 0.14 & \multicolumn{2}{|c|}{$\begin{array}{l}\text { Esnaola et al., } 2001 \text { (Esnaola et al., } \\
\text { 2001) }\end{array}$} & 39 & 31 \\
\hline Surgery & 0.35 & $0.13-0.92$ & $0.034^{*}$ & \multicolumn{2}{|c|}{ Little et al., 2002 (Little et al., 2002) } & 82 & 44 \\
\hline Chemotherapy & 0.31 & $0.13-0.74$ & $<0.01 *$ & \multirow{2}{*}{\multicolumn{2}{|c|}{$\begin{array}{l}\text { Ferrari et al., } 2003 \text { (Ferrari et al., } \\
\text { 2003) }\end{array}$}} & & \\
\hline & & & & & & 171 & 40 \\
\hline
\end{tabular}

to undergo curative resection.

Survival

The median follow-up time for survivors was 88 months (range, 11-150 months). The median survival time was 9.33 months $(95 \% \mathrm{CI}$; 5.6-13.1). The overall survival rates at $1,2,5$ years were $38.2 \%, 23.5 \%$, and 20.6 $\%$ (Figure 2A). The median survival time was longer in younger patients ( $\leq 20$ years) but did not reach statistical significant level; 20.97 vs. 6.77 months, $\mathrm{p}=0.16$ (Figure 2B). Likewise, histological subtype was not a significant prognostic factor for survival, with the best survival observed in embryonal subtype of 19.0 months. Primary site, size, and nodal involvement were not significantly

$\mathrm{EFS}=$ event-free survival

associated with overall survival either.

Patients who underwent surgery had a significant longer survival; $10.57 v s .4 .57$ months (HR 0.32, $\mathrm{p}<0.01$ ). Similarly, incorporating chemotherapy in the course of treatment was associated with a better survival; 20.97 vs. 4.7 months (HR $0.28, \mathrm{p}<0.01)$ as shown in figure $2 \mathrm{C}$ and 2D.

\section{Multivariate analysis}

Table 3 presents the results of a multivariate logistic regression analysis for survival which age group, tumor size, nodal involvement, stage at diagnosis and treatment 
modality were entered. Patients who underwent surgery appeared to have a better survival than those who did not (HR 0.35, $\mathrm{p}=0.034$ ). Those who received neoadjuvant, adjuvant, or palliative chemotherapy were at lower risk for death as compared with those who did not with the HR of $0.31, p=0.008$. Younger adults ( $\leq 20$ years old), those with smaller tumor size $(\leq 5 \mathrm{~cm})$, nodal involvement and metastatic disease were also at higher risk but did not reach significant level in this multivariate model.

\section{Discussion}

In this series, we found that the survival outcome for adult RMS was poor especially in patients who presented with metastatic disease. The median overall survival was 9.33 months and the 5-year survival rate was $20.6 \%$. Surgery and chemotherapy in the treatment course significantly improved long term survival.

Comparing with other reported series (Table 4), the 5 -year survival rate in this study was relatively poor (20.6\% vs. 32-44\%). In our institution, patients often present with an advanced disease with a third of patients had distant metastases at the time of presentation. The lack of multimodality treatment would also explain the poor outcome, with only half of the patients received chemotherapy. The reasons for this surprisingly low proportion could be poor performance status from high tumor burden, uneventful surgical complications, and the cost of chemotherapy. Moreover, neoadjuvant chemotherapy was administered to only six patients.

Whether older age is an adverse prognostic factor in adult RMS remains unanswered. Hawkins et al. reported that in both univariate and multivariate analyses, increasing age resulted in shorter survival (Hawkins et al., 2001). Nevertheless, in the current study there was a trend but we were unable to show a statistically significant association between age and survival, which resulted from the small number of patients. Most of the tumors arose from extremity (35\%) and head and neck region (29\%) which differs slightly from other series. In the report by Little et al., head and neck RMS was found in $50 \%$ of the patients and in the report by Hawkins et al., most of the tumors were from visceral in origin (Hawkins et al., 2001; Little et al., 2002). The outcome of nodal involvement and metastatic RMS was extremely poor which is similar to other adult and pediatric RMS series (Ferrari et al., 2003).

In the present study, along with other adult RMS series, the pleomorphic subtype increases with older age (Hawkins et al., 2001; Ferrari et al., 2003; Stock et al., 2009). Pleomorphic RMS is an aggressive subtypes and may not respond well to chemotherapy as other subtype of RMS. Currently, the NCCN guideline recommends the treatment for pleomorphic RMS according to soft tissue sarcoma guidelines (National Comprehensive Cancer Network). In this study, however, pleomorphic RMS patients received the same regimen as other RMS patients but data regarding the response of chemotherapy according to tumor subtypes.

In conclusion, outcome of adult RMS was poor. Given the result, incorporating surgery and chemotherapy should be encouraged in all patients if feasible. Improvement of surgical technique and efficacy of chemotherapy would result in a better survival.

\section{Acknowledgements}

We wish to acknowledge the support the Cancer Research Group, Khon Kaen University, Thailand.

\section{References}

Ariel IM, Briceno M (1975). Rhabdomyosarcoma of the extremities and trunk: analysis of 150 patients treated by surgical resection. J Surg Oncol, 7, 269-87.

Arndt CA, Hawkins DS, Meyer WH, et al (2008). Comparison of results of a pilot study of alternating vincristine/doxorubicin/ cyclophosphamide and etoposide/ifosfamide with IRS-IV in intermediate risk rhabdomyosarcoma: a report from the Children's Oncology Group. Pediatr Blood Cancer, 50, 33-6.

Arndt CA, Stoner JA, Hawkins DS, et al (2009). Vincristine, actinomycin, and cyclophosphamide compared with vincristine, actinomycin, and cyclophosphamide alternating with vincristine, topotecan, and cyclophosphamide for intermediate-risk rhabdomyosarcoma: children's oncology group study D9803. J Clin Oncol, 27, 5182-8.

Esnaola NF, Rubin BP, Baldini EH, et al (2001). Response to chemotherapy and predictors of survival in adult rhabdomyosarcoma. Ann Surg, 234, 215-23.

Ferrari A, Dileo P, Casanova M, et al (2003). Rhabdomyosarcoma in adults. A retrospective analysis of 171 patients treated at a single institution. Cancer, $\mathbf{9 8}, 571-80$.

Hawkins WG, Hoos A, Antonescu CR, et al (2001). Clinicopathologic analysis of patients with adult rhabdomyosarcoma. Cancer, 91, 794-803.

Little DJ, Ballo MT, Zagars GK, et al (2002). Adult rhabdomyosarcoma: outcome following multimodality treatment. Cancer, 95, 377-88.

National Comprehensive Cancer Network. Soft Tissue Sarcoma (Version 1.2015) [Online].

Newton WA, Jr., Gehan EA, Webber BL, et al (1995). Classification of rhabdomyosarcomas and related sarcomas. Pathologic aspects and proposal for a new classification--an Intergroup Rhabdomyosarcoma Study. Cancer, 76, 1073-85.

Parham DM, Ellison DA (2006). Rhabdomyosarcomas in adults and children: an update. Arch Pathol Lab Med, 130, 1454-65.

Sezgin G, Acipayam C, Bayram I, et al (2015). Replacing actinomycin-D with Carboplatin for newly diagnosed rhabdomyosarcoma. Asian Pac J Cancer Prev, 16, 3351-4.

Simon JH, Paulino AC, Ritchie JM, et al (2003). Presentation, prognostic factors and patterns of failure in adult rhabdomyosarcoma. Sarcoma, 7, 1-7.

Stock N, Chibon F, Binh MB, et al (2009). Adult-type rhabdomyosarcoma: analysis of 57 cases with clinicopathologic description, identification of 3 morphologic patterns and prognosis. Am J Surg Pathol, 33, 1850-9.

Sultan I, Qaddoumi I, Yaser S, et al (2009). Comparing adult and pediatric rhabdomyosarcoma in the surveillance, epidemiology and end results program, 1973 to 2005: an analysis of 2,600 patients. J Clin Oncol, 27, 3391-7. 